ANIMAL BEHAVIOUR

\section{Infidelity yields better offspring}

Sexual promiscuity in female songbirds increases the reproductive success of their offspring.

Nicole Gerlach at Indiana University in Bloomington and her colleagues studied free-living dark-eyed juncos (Junco hyemalis). The birds form a 'social pair' with one partner but produce more than one-quarter of their offspring from 'extra-pair' mating. These young go on to reproduce more successfully than those sired within the social pair.

As adults, the male offspring from extra-pair matings were found to be more promiscuous than their social-pair counterparts. Female extra-pair offspring weren't - but did go on to produce more offspring with their social partners. The authors conclude that the genetic advantage of multiple sex partners may not be apparent in traits in the early life of the offspring, but might instead affect their reproductive success as adults.

Proc. R. Soc. B http://dx.doi. org/10.1098/rspb.2011.1547 (2011)

\section{NEUROBIOLOGY}

\section{Cell death from failure of DNA fix}

A sluggish DNA-repair system in mice is sufficient to reproduce the pathology and symptoms typical of neurodegenerative diseases.

Ype Elgersma and Dick Jaarsma at the Erasmus University Medical Center in Rotterdam, the Netherlands, and their colleagues deleted a gene in mice that is

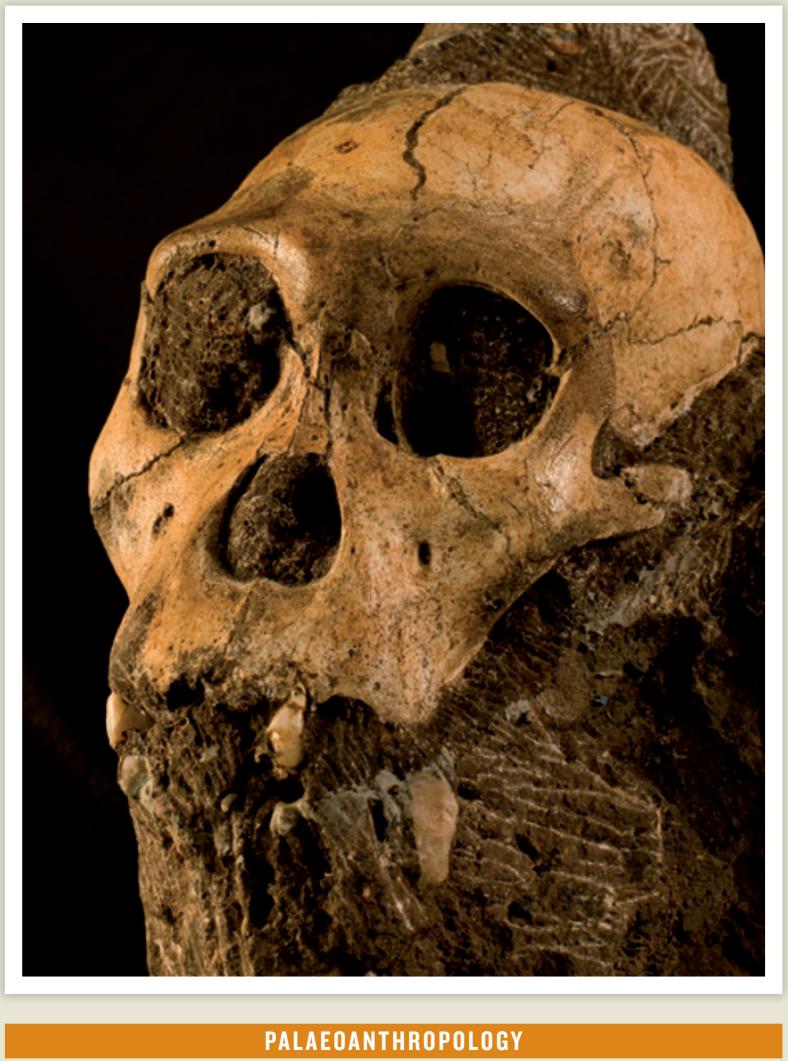

\title{
A mixture of old and new
}

Some two-million-yearold fossils from South Africa could reshuffle the family tree of early human ancestors. Two fossils from a recently discovered hominin species called Australopithecus sediba show human-like features typically seen in later fossils.

Lee Berger at the

University of the

Witwatersrand in

Johannesburg, South Africa, and his team first discovered the remains (pictured) in a cave near Johannesburg in 2008. Now, a closer look at two $A$. sediba individuals, a boy and a woman, uncovers an assortment of primitive and modern traits, such as a small brain with a front portion shaped like a human's. A. sediba's squat pelvis looks modern, casting doubt on the idea that this form evolved to give birth to large-brained babies. Its long, ape-like arms bear human-like hands with long thumbs adapted for gripping. A. sediba walked on two feet; its ankle resembles a human's, but its heel and shin bones look like a chimpanzee's.

Berger's team says that A. sediba could be the direct ancestor of Homo erectus, and so of modern humans. Alternatively, the fossils may mark a late-surviving form of Australopithecus that later went extinct.

Science 333, 1402-1407, 1407-

1411, 1411-1417, 1417-1420, 1421-1423 (2011) crucial to three DNA-repair mechanisms. Young adult mice developed learning and memory problems, and their neurons were less able to form strong connections with one another than were those of non-mutated mice of the same age. The mutant brains also showed signs of cell death and neurodegeneration.

The authors say that the accumulation of DNA damage may contribute directly to cognitive decline and pathology in conditions such as Alzheimer's disease.

J. Neurosci. 31, 12543-12553 (2011)

MICROBIOLOGY

\section{Stomach bacteria} break DNA strands

Stomach ulcers are caused by chronic infection with the Helicobacter pylori bacterium, which is also the leading risk factor for stomach cancer. One reason for the cancer risk could be that the pathogen creates breaks in the DNA molecules of infected cells, according to teams led by Massimo Lopes and Anne Müller at the University of Zurich in Switzerland.

The authors incubated mouse and human cells with the bacteria and found that the cells' DNA fragmented in a manner consistent with double-strand breakage. The breakage was dependent on direct contact between the cells and the bacteria, and was repaired by normal cellular machinery once the infection was over. However, when infection lasted for 48 hours or more, $70 \%$ of the cells stopped dividing, suggesting that continuous infection might overwhelm the DNArepair mechanism. 